\title{
Structural variation of the Bonin ridge revealed by modeling of seismic and gravity data
}

\author{
Shuichi Kodaira ${ }^{1}$, Toshiya Fujiwara ${ }^{2}$, Naoto Noguchi ${ }^{1}$, and Narumi Takahashi ${ }^{1}$ \\ ${ }^{1}$ Institute for Research on Earth Evolution, Japan Agency for Marine-Earth Science and Technology, \\ Showa-machi 3173-25, Kanazawa-ku, Yokohama 236-0001, Japan \\ ${ }^{2}$ Institute for Research on Earth Evolution, Japan Agency for Marine-Earth Science and Technology, \\ Natsushima-cho 2-15, Yokosuka 237-0061, Japan
}

(Received February 3, 2011; Revised April 28, 2011; Accepted June 21, 2011; Online published January 26, 2012)

\begin{abstract}
A previous study of a longitudinal profile along the Bonin ridge concluded that remarkably thin forearc crust $(<10 \mathrm{~km}$ thick) along the northern half of the ridge indicates that the crust there was formed by forearc spreading during the initial stage of subduction along the Izu-Bonin intra-oceanic arc. However, a profile across the Bonin ridge shows a thicker crust. In this study, we construct a model that takes into account seismic and gravity data from both profiles. Re-modeling of the seismic data showed a north-south aligned area of thin crust $(\sim 10$ $\mathrm{km}$ thick) at the center of the Bonin ridge; this structure was confirmed by gravity data. The seismic data at the eastern end of the across-arc profile suggests that the crust thickens beneath the trenchward slope of the Bonin ridge. However, a petrological model suggests a trenchward extension of forearc oceanic crust that formed during the initial stage of subduction. Although further detailed investigation is required, we suggest that this contradiction can be explained either by the subduction of buoyant crust immediately beneath the forearc oceanic crust, or by the presence of a serpentinized mantle wedge beneath the forearc oceanic crust.
\end{abstract}

Key words: Seismic imaging, gravity, forearc, Bonin ridge, subduction zone.

\section{Introduction}

The Izu-Bonin-Mariana (IBM) intra-oceanic arc, where the Pacific plate is subducting beneath the Philippine Sea plate, extends over $2800 \mathrm{~km}$ from central Japan in the north to Guam in the south (Fig. 1) and has long been studied to examine the evolution of arc crust. The ages of the basement rocks of the forearc indicate that, in this arc system, subsidence of the Pacific plate began at about $50 \mathrm{Ma}$. Single-arc volcanism continued until rifting started in the Parece Vela basin at $30 \mathrm{Ma}$ and the Shikoku basin farther north at $25 \mathrm{Ma}$. These back-arc spreading systems met at $20 \mathrm{Ma}$ and spreading stopped at about $15 \mathrm{Ma}$ (e.g., Stern and Bloomer, 1992). The back-arc spreading process formed the Kyushu-Palau Ridge as a remnant arc at the western edge of the Parece Vela and Shikoku basins. Backarc rifting along the Mariana trough started at $10 \mathrm{Ma}$, and the consequent seafloor spreading began at 3-4 Ma (Bibee et al., 1980; Yamazaki and Yuasa, 1998). In the Izu arc, intra-arc rifting started to the west of the present-day volcanic front at $2 \mathrm{Ma}$ (e.g., Ishizuka et al., 2002).

As discussed in previous studies (e.g., Stern and Bloomer, 1992; Pearce et al., 1992; Ishizuka et al., 2006), the magmatism and structure of the forearc of the IBM system provide fundamental information about the initiation of subduction as well as magmatic processes in an in-

Copyright (C) The Society of Geomagnetism and Earth, Planetary and Space Sciences (SGEPSS); The Seismological Society of Japan; The Volcanological Society of Japan; The Geodetic Society of Japan; The Japanese Society for Planetary Sciences; TERRAPUB.

doi:10.5047/eps.2011.06.036 fant arc. The most prominent topographic feature along the forearc in the Izu-Bonin region is the Bonin ridge (Fig. 1), a north-south trending massif about $400 \mathrm{~km}$ long and bounded by the Ogasawara trough to the west and the Izu-Bonin trench to the east. The oldest known volcanic activity in the IBM arc system occurred on the Bonin ridge at Chichi-jima and Muko-jima (Fig. 1). ${ }^{40} \mathrm{Ar} /{ }^{39} \mathrm{Ar}$ dates imply that there were brief periods of Eocene (46-48 Ma) boninitic volcanism on both islands, which were caused by the melting of depleted mantle at shallow levels, aided by the introduction of hydrous fluids from a sinking oceanic plate (Ishizuka et al., 2006). On the other hand, normal arc volcanism (i.e., tholeiitic-calcalkaline andesitic volcanism) occurred at Haha-jima, $40 \mathrm{~km}$ south of Chichi-jima, and boninite has not been reported there (e.g., Taylor and Nesbitt, 1995). ${ }^{40} \mathrm{Ar} /{ }^{39} \mathrm{Ar}$ dates show that the tholeiiticcalcalkaline andesitic volcanism at Haha-jima occurred at about 41-45 Ma, that is, 2-3 Ma after the boninitic magmatism at Chichi-jima and Muko-jima. According to Ishizuka et al. (2006), the petrological data indicate that the process of crustal formation in the Izu-Bonin forearc changed at around $45 \mathrm{Ma}$ in response to a change of the composition and melting conditions of the sub-arc mantle.

\section{Previous Seismic Studies}

The importance of seismic data for understanding the crustal composition of island arcs has been recognized since a layer of $P$-wave velocity $6 \mathrm{~km} / \mathrm{s}$ was identified under the northern Izu arc by Suyehiro et al. (1996). Since then, a series of high-resolution deep seismic studies in the IBM arc have presented new insights into the formation of arc crust 


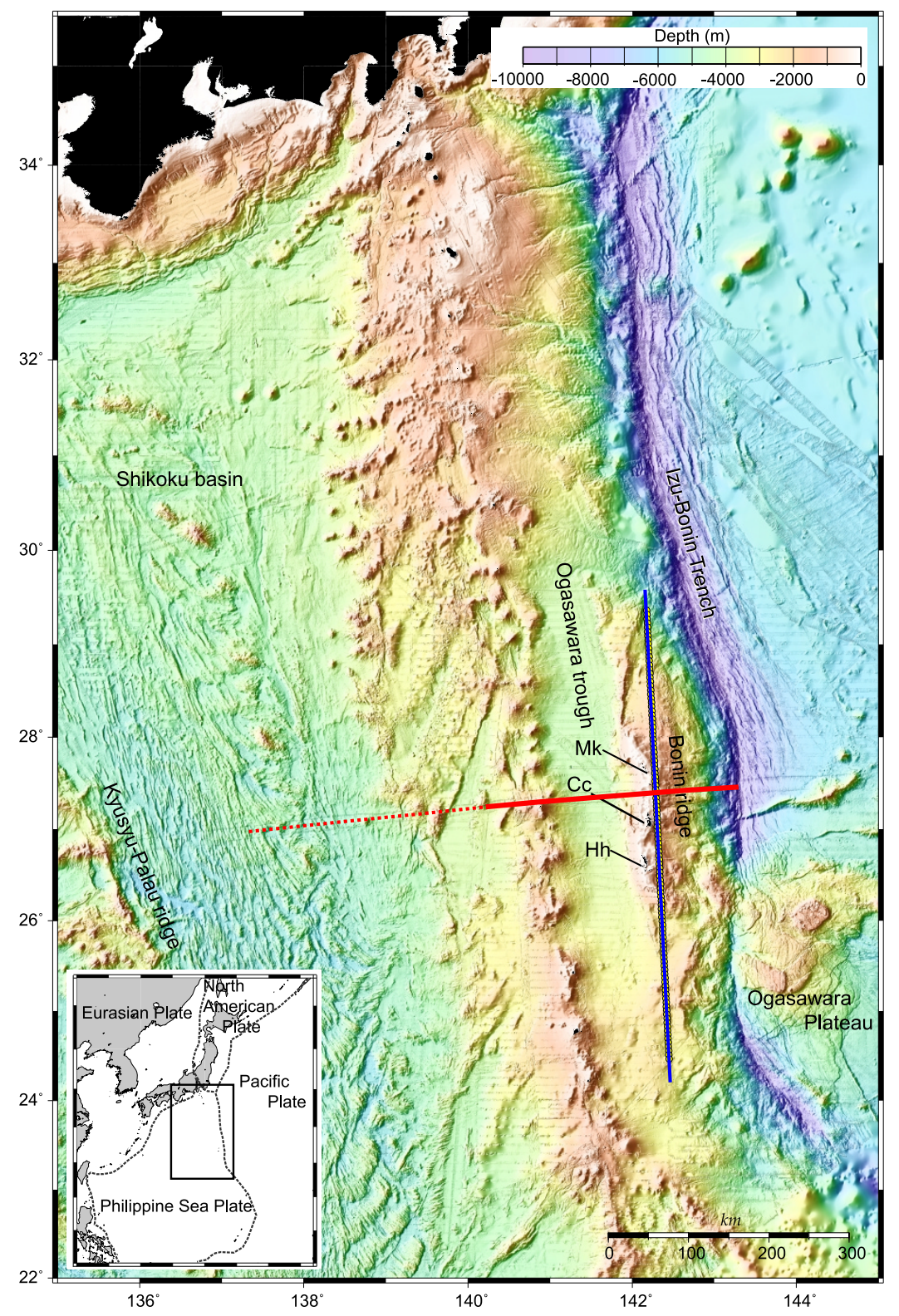

Fig. 1. Regional tectonic setting and detailed map of the study area showing the location of the wide-angle seismic profiles. Blue and red lines indicate seismic profiles OGr1 (processed by Kodaira et al., 2010) and SPr2 (processed by Takahashi et al., 2009), respectively. Only the eastern half of line SPr2 (red solid line) was re-modeled in this study. Cc, Chichi-jima; Hh, Haha-jima; Mk, Muko-jima.

(e.g., Kodaira et al., 2007a, b, 2008; Takahashi et al., 2007, 2008a; Calvert et al., 2008; Tatsumi et al., 2008; Sato et al., 2009). A seismic image along the volcanic front of the Izu arc (Kodaira et al., 2007a) shows a layer of arc crust (more than $30 \mathrm{~km}$ thick) for which the $P$-wave velocity $(6.0-6.8 \mathrm{~km} / \mathrm{s})$ is greater beneath basaltic volcanoes than beneath rhyolitic volcanoes. This observation implies that this layer, interpreted to be of felsic to intermediate composition, has formed predominantly under the basaltic volcanoes. A seismic study along the rear-arc of the Izu arc (Kodaira et al., 2008) shows marked variations of crustal thickness that are attributed mainly to thickness variations of the middle crustal layer of $P$-wave velocity $6.0-6.8 \mathrm{~km} / \mathrm{s}$. Kodaira et al. (2008) proposed that the rear-arc crust is composed of a remnant arc crust that was separated from the volcanic front, probably in the Oligocene, and that most of the rear-arc crust was created before separation from the volcanic front.

Takahashi et al. (2009) provided an image from a seismic reflection/refraction profile across the central Izu-Bonin arc, which crossed three arcs of different ages: the Eocene forearc (Bonin ridge), the present arc (volcanic front), and the Oligocene rear-arc. For the Eocene arc crust, they observed seismic velocities of $6.4-6.6$ and $6.8-7.4 \mathrm{~km} / \mathrm{s}$ in the middle and lower crust, respectively, whereas those of the current volcanic front were slower $(5.7-6.5 \mathrm{~km} / \mathrm{s}$ for the middle crust and $6.7-7.1 \mathrm{~km} / \mathrm{s}$ for the lower crust). According to known petrologic studies, these structural differences reflect different mechanisms of crustal growth in areas of basaltic and andesitic magmas.

A recent seismic study along the Bonin ridge (Kodaira et al., 2010) revealed striking structural variation along the Bonin ridge. The seismic data show a remarkably thin crust $(<10 \mathrm{~km}$ thick) along the northern half of the Bonin ridge 


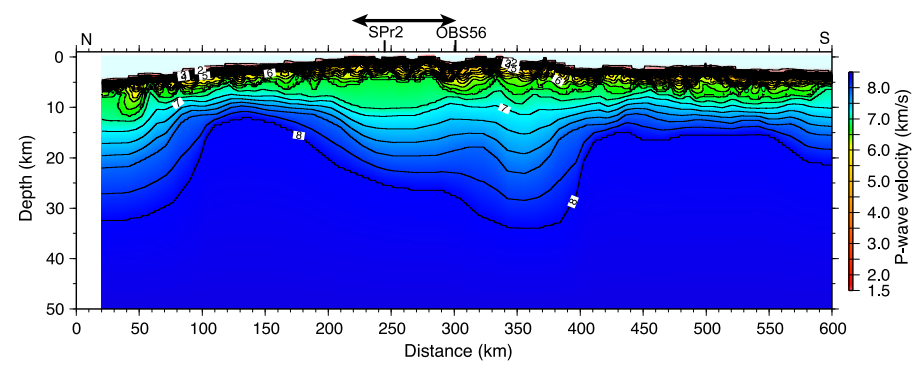

Fig. 2. Model of line OGr1 modified to match the crustal structure shown by line SPr2. The arrows indicate the area where the crust was thickened to be consistent with the structure shown by line SPr2 (Takahashi et al., 2009).

(beneath Chichi-jima and Muko-jima) and abrupt crustal thickening (to $\sim 20 \mathrm{~km}$ ) toward the south of the ridge (beneath Haha-jima). Velocity-depth profiles of the thin forearc crust of the Bonin ridge were seismologically identical to those of typical oceanic crust. This observation strongly supports the view that forearc oceanic crust along the IzuBonin intra-oceanic arc was formed by forearc spreading during the initial stage of subduction (Kodaira et al., 2010).

However, Kodaira et al. (2010) pointed out that the seismic structure modeled to the north of Chichi-jima was not entirely consistent with the structure across the Bonin ridge reported by Takahashi et al. (2009). The ridge-parallel profile of Kodaira et al. (2010) and the cross-ridge profile of Takahashi et al. (2009) intersect between Chichi-jima and Muko-jima, where the ridge-parallel profile shows a crust of about $10 \mathrm{~km}$ thickness, and the cross-ridge profile shows a crust of about $18 \mathrm{~km}$ thickness. Kodaira et al. (2010) gave three possible explanations for this inconsistency: differences in the initial models used, the effect of smoothing during inversion, or edge effects in the modeling. However, they did not further investigate the differences of the structures derived from the two seismic profiles. In this study, we have re-modeled the seismic data from both the cross-ridge (SPr2) and ridge-parallel (OGr1) profiles to further examine the three-dimensional structure, and further constrained the resultant model with gravity modeling.

\section{Re-modeling of Seismic Data}

The two sets of seismic data (SPr2 and OGr1; Fig. 1) used in this study were acquired with the same seismic system (Takahashi et al., 2009; Kodaira et al., 2010). Eight 1500 -in $^{3}$ airguns (total volume $197 \mathrm{~L}$ ) were fired at 200$\mathrm{m}$ intervals along both profiles. The ocean bottom seismographs (OBSs) for both lines were $4.5-\mathrm{Hz}$ three-component gimbal-mounted geophones and hydrophones, and 16-bit digital data were continuously recorded to a maximum frequency of $100 \mathrm{~Hz}$ (Shinohara et al., 1993; Kanazawa and Shiobara, 1994). OBSs were deployed at approximately 5$\mathrm{km}$ intervals along both lines, $105 \mathrm{OBSs}$ on line SPr2 and 110 OBSs on line OGr1. Detailed descriptions of data acquisition and processing are provided by Takahashi et al. (2008b, 2009) and Kodaira et al. (2010).

As described above, line OGr1 (Kodaira et al., 2010) revealed a crust of less than $10 \mathrm{~km}$ thickness at its intersection with line SPr2 (Takahashi et al., 2009) north of Chichijima, whereas line SPr2 showed a thickness of about $18 \mathrm{~km}$ of crust at the intersection. Because both the structure and seismic character revealed by line OGr1 were simpler than those of SPr2, we first modified the structural model for line OGr1 to match the crustal thickness observed on line SPr2 by using the forward ray-tracing technique of Zhang and Toksöz (1998). For this test, the modified model was created from a smoothed version of the original structural model of line OGr1, but the crust between Chichi-jima and Muko-jima (220-300 km) was made thicker to match the structure shown by line SPr2 (Takahashi et al., 2009) at its intersection with line OGr1 (Fig. 2). The synthetic travel times calculated for this model (Fig. 3) were more than $1 \mathrm{~s}$ slower than those for the original model. Because the seismic data north of Chichi-jima show a simple character indicating a flat layered structure (see data provided by Kodaira et al., 2010), we believe that local thickening of the crust close to the line intersection is not plausible.

Next, we tested modifications of the model for line SPr2, seeking one that explained the observed data from both seismic profiles. In these tests, we did not modify the original model for the western half of line SPr2 $(0-250 \mathrm{~km})$ because no seismic arrivals from that part of the model would have reached the Bonin ridge. For the first modification, we used a crustal thickness of $10 \mathrm{~km}$ to the east of the Bonin ridge (Fig. 4) to match exactly the structure of line OGr1. The synthetic travel times calculated from the modified model (Fig. 4) became faster toward the eastern side of the profile where the $10-\mathrm{km}$-thick crust was modeled. This misfit of travel times indicated that thickening the crust toward the east from the Bonin ridge might provide a better fit, so we further modified the model by increasing the crustal thickness eastward from $10 \mathrm{~km}$ at the line intersection to $15 \mathrm{~km}$ about $50 \mathrm{~km}$ from the line intersection (Fig. 5). The synthetic travel times calculated from this model showed smaller travel-time misfits than those from the previous model, but were still $0.5 \mathrm{~s}$ faster than those of the original model.

To attempt to obtain a better travel-time fit, we again modified the model for line SPr2 by shortening the distance over which the crust beneath the ridge thickened eastward from 10 to $15 \mathrm{~km}$ to a distance of $\sim 20 \mathrm{~km}$ (Fig. 6). The travel-time fit for this model was as good as that of the original model, indicating that both the original model for line SPr2 and the final modification explain the observed data, but that the final modification provided an even more reasonable model because the modeled structures on both lines at the intersection point were identical.

To further fine-tune the velocity model, we applied to- 

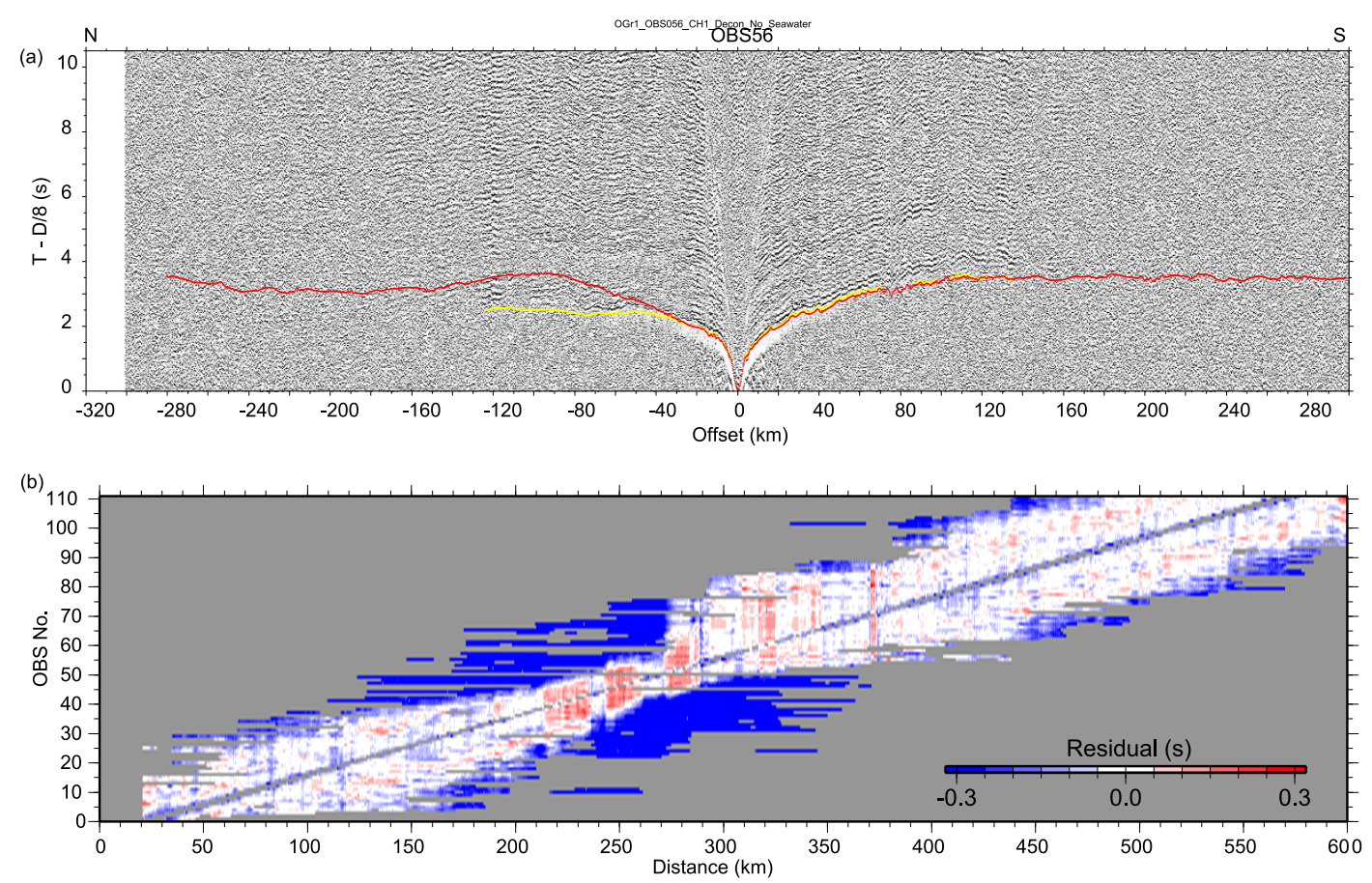

Fig. 3. (a) An example of data recorded by an OBS (OBS56) on line OGr1. Calculated travel-time curves of the original model (yellow line) and the modified model (Fig. 2) are superimposed. (b) Travel-time residuals calculated from the modified model (Fig. 2) for each shot at each OBS on line OGr1.
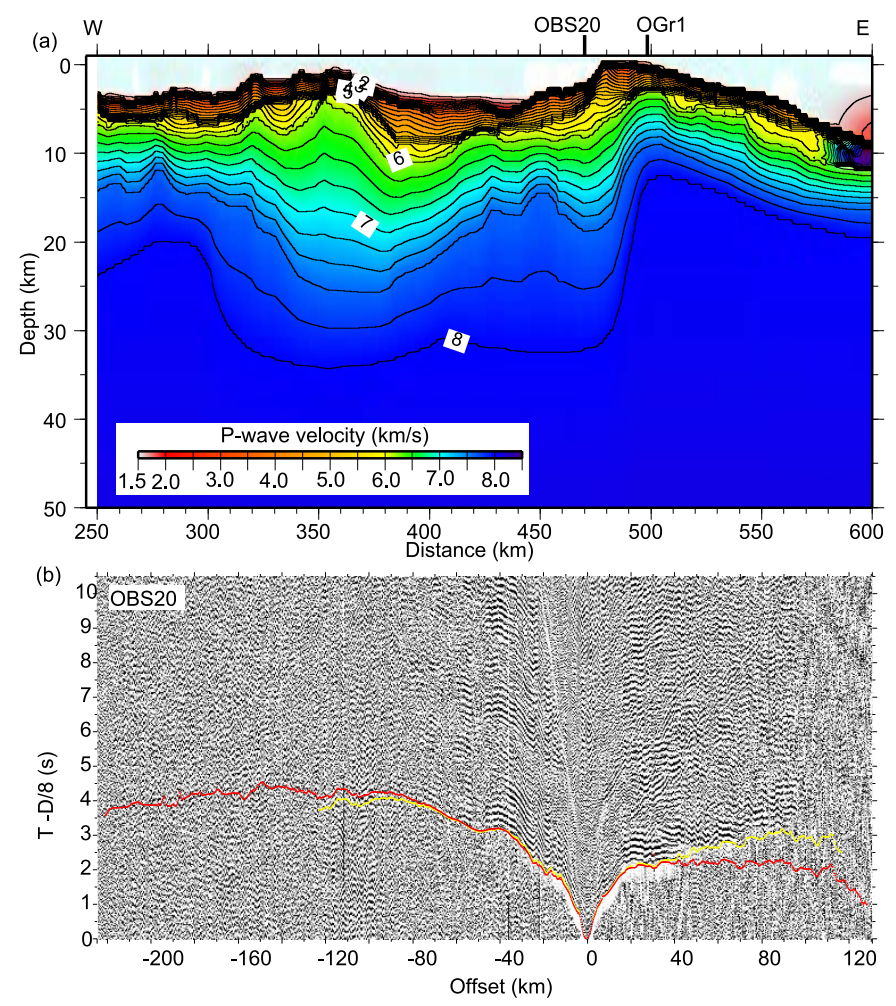

Fig. 4. (a) First modified model of line SPr2. (b) An example of data recorded at an OBS on line SPr2. Calculated travel-time curves of the original model (yellow line) and the modified model (Fig. 4(a)) are superimposed.

mographic inversion (Zhang and Toksöz, 1998) to the data from SPr2 using the final modification of the model for line SPr2 as an initial model. For this inversion, we reexamined some of the travel times picked at OBSs farther than $\sim 40 \mathrm{~km}$ from the Bonin ridge. The tomographic inver- sion results showed almost the same structure as the initial model, but with smaller structural perturbations (Fig. 7). The travel-time fits for all of the OBSs used in the tomographic inversion appeared to be slightly better than those for the original model, but the difference was not significant 

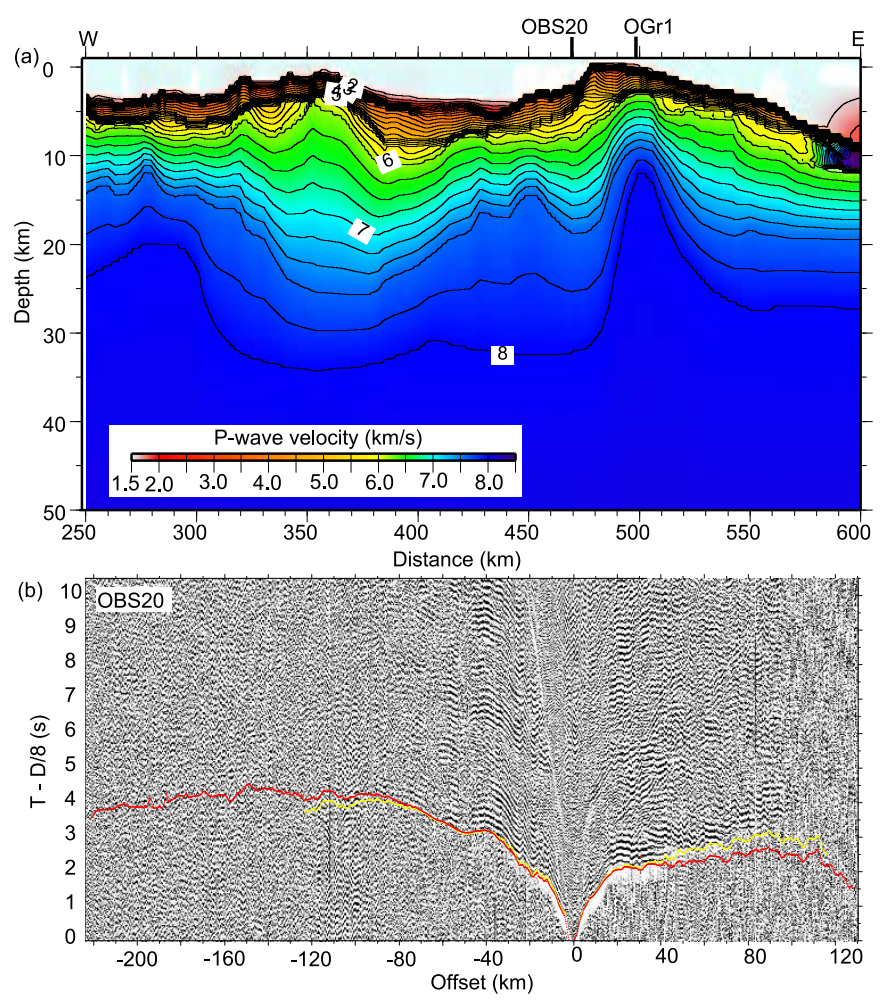

Fig. 5. (a) Second modified model of line SPr2. (b) An example of data recorded at an OBS on line SPr2. Calculated travel-time curves of the original model (yellow line) and the modified model (Fig. 5(a)) are superimposed.
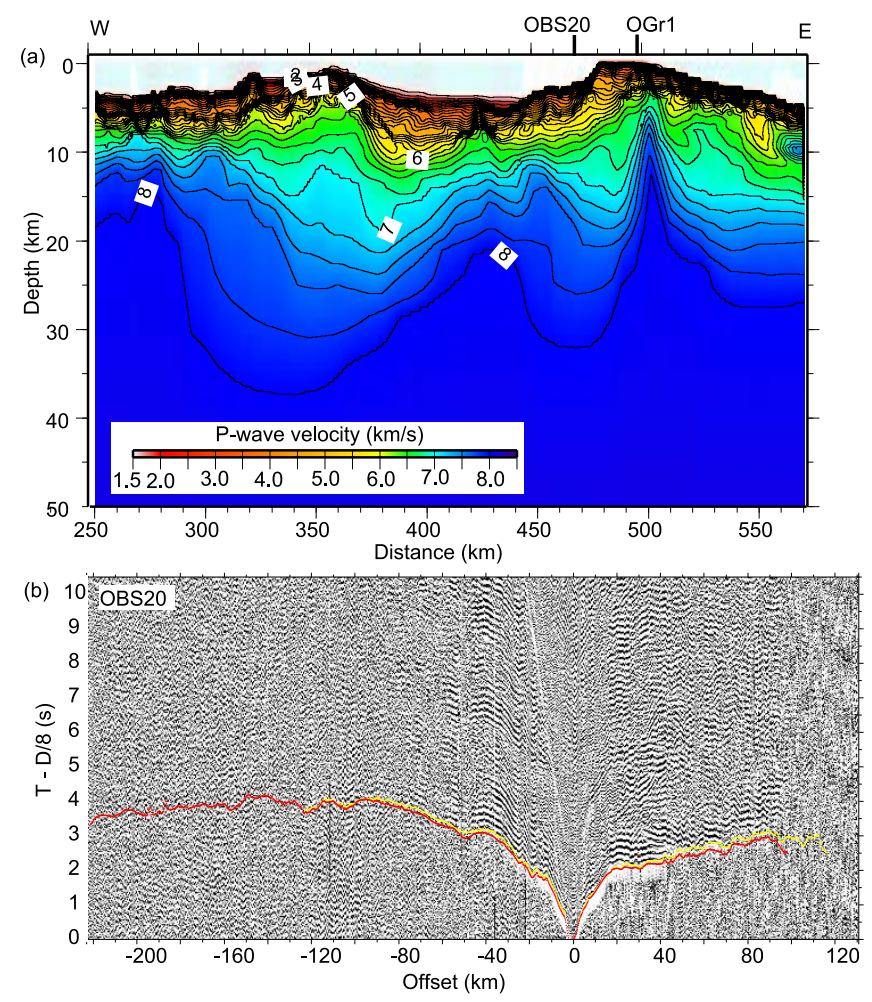

Fig. 6. (a) Third modified model of line SPr2. (b) An example of data recorded at an OBS on line SPr2. Calculated travel-time curves of the original model (yellow line) and the modified model (Fig. 6(a)) are superimposed. 

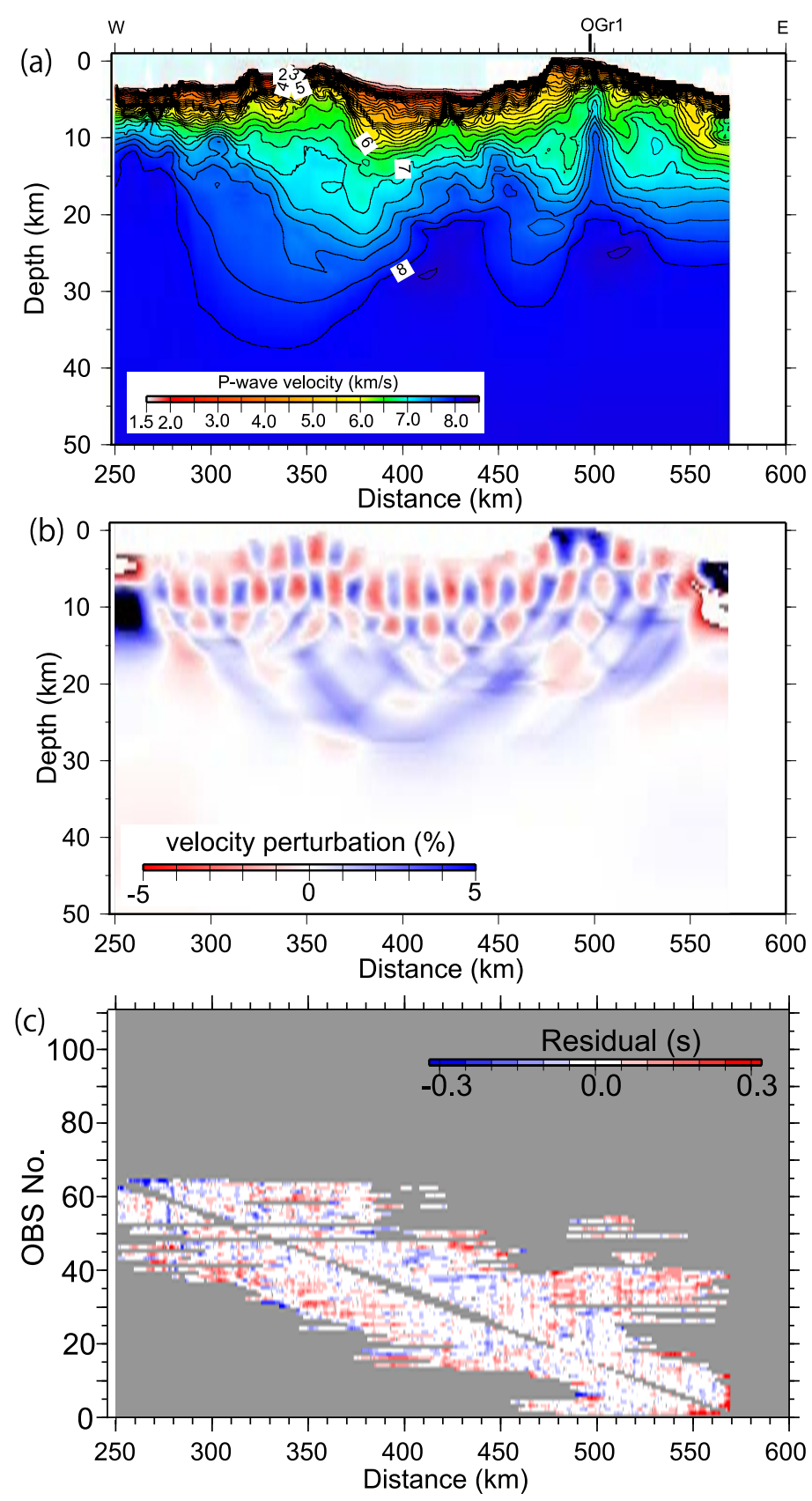

Fig. 7. (a) Final model of SPr2 obtained by tomographic inversion. The initial model for the tomography is shown in Fig. 6(a). (b) Checkerboard test. (c) Travel-time residuals calculated from the final model (Fig. 7(a)) for each shot at each OBS for the eastern half of line OGr1.

(cf. figure 8(c) and figure 5 of Takahashi et al., 2009).

To assess the resolution of the model for line SPr2, we applied a checkerboard test (Fig. 7(b)) using the same procedure as used previously for lines OGr1 and SPr2 (Takahashi et al., 2009; Kodaira et al., 2010), but, here, we used a finer checkerboard pattern (i.e., a $10 \mathrm{~km}$ horizontal by $5 \mathrm{~km}$ vertical pattern to $15 \mathrm{~km}$ depth). The checkerboard test showed good recovery beneath the Bonin ridge for the final modification of the model for line SPr2, but the eastern edge of the model $(520-570 \mathrm{~km})$ was not resolved at depths greater than $10 \mathrm{~km}$.

\section{Gravity Modeling}

To confirm the structures shown by seismic data around the Bonin ridge, we calculated gravity anomalies using density data derived from the seismic data and compared them to gravity data recorded over the Izu-Bonin arc by the Hydrographic Department of Japan and the Geological Survey of Japan. The shipboard gravity data are available via the NOAA National Geophysical Data Center. The observed free-air gravity anomaly data were merged with gravity anomaly data derived from satellite altimetry (Sandwell and Smith, 1997). During the gravity modeling in this study, we aimed to fit the long-wavelength gravity anomaly.

A notable feature of the free-air gravity map of the study area is a prominent gravity high $(>+350 \mathrm{mGal})$ over the 


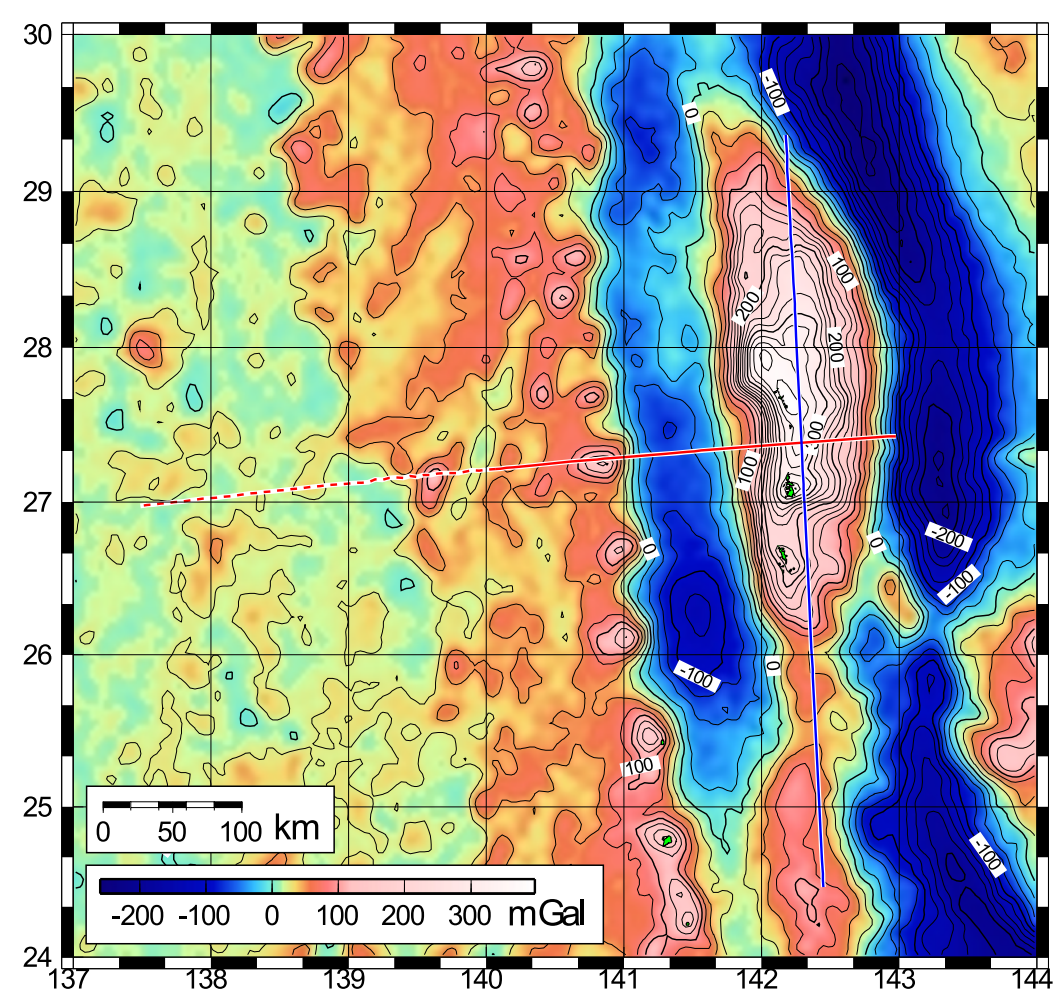

Fig. 8. Free-air gravity anomaly map of the study area. Blue and red lines indicate lines OGr1 and SPr2, respectively. Although gravity modeling was done for all of line SPr2, the results are shown here for only the eastern half of the profile (solid red line).

Bonin ridge (Fig. 8). This prominent gravity anomaly has been of longstanding interest (e.g., Honza and Tamaki, 1985). Ishihara et al. (1981) suggested that the anomaly reflects either an uplift of the Moho boundary beneath the Bonin ridge, or the presence of a high-density crust beneath the ridge.

Free-air gravity data primarily reflect density contrasts caused by variations of seafloor topography, but subseafloor density structures can also produce gravity anomalies. We calculated the theoretical gravity anomaly that would represent the crustal structure which we determined from the seismic data. Two-dimensional density structures were created for each profile, including seafloor topography, as a set of rectangular prisms, each $0.5 \mathrm{~km}$ long $\times$ $0.5 \mathrm{~km}$ wide and horizontally infinite in the direction normal to the profile. The $P$-wave velocities were converted to densities using the velocity-density relationship of Ludwig et al. (1970) and the water density was set at $1030 \mathrm{~kg} / \mathrm{m}^{3}$. The gravity anomaly was calculated using the formula of Blakely (1996). The density structures at both ends of the two profiles were extended by sufficiently long distances $(300 \mathrm{~km})$ to avoid artificial edge effects. It should be noted that the densities at the intersection are not exactly identical between the two profiles. This is because the original seismic velocity models at the intersection are not exactly the same. This difference of the seismic velocity may reflect several factors, such as local inhomogeneity and anisotropy which cannot be resolved by the observed seismic data.

The effect of the long-wavelength gravity anomaly produced by the subducting Pacific plate on the gravity model was estimated using a three-dimensional subducting slab model. The thickness of the slab was set at $90 \mathrm{~km}$, and the density contrast between the slab and the surrounding mantle was assumed to be $+65 \mathrm{~kg} / \mathrm{m}^{3}$ in accordance with a previous study by Furuse and Kono (2003). A crustal layer of $2800-3000 \mathrm{~kg} / \mathrm{m}^{3}$ density was placed above the dense slab. The subducting plate was modeled as a set of prisms of $10 \mathrm{~km} \times 10 \mathrm{~km}$ widths. The depth of the slab was estimated from a deep seismic plane down to $\sim 500$ $\mathrm{km}$ depth (International Seismological Centre, 2001) and a plate interface imaged from seismic data by Takahashi et al. (2009). Along the north-south profile (line OGr1), the position of the subducting plate at depths of $\sim 30-35 \mathrm{~km}$ was interpreted from seismic reflections (Kodaira et al., 2010). The density model for line OGr1 also incorporated the subducted plate at depths of $\sim 30-35 \mathrm{~km}$.

Gravity anomalies calculated from the density models of line SPr2, derived from both the original velocity model and the preferred velocity model, were superimposed on the observed free-air gravity anomaly (Fig. 9). Both calculated gravity anomalies explain well the observed free-air gravity anomaly from the Shikoku basin to the western flank of the Bonin ridge. However, at the center of the Bonin ridge, the gravity anomaly derived from the original velocity model is $\sim 50 \mathrm{mGal}$ lower than the observed data. In comparison, the gravity anomaly derived from the preferred velocity model fits well the observed data, even in the center of the Bonin ridge where the crustal thickness is $\sim 10 \mathrm{~km}$. Thus, both the seismic and gravity modeling indicate that there is a northsouth aligned zone of thin crust ( $\sim 10 \mathrm{~km}$ thick) along the axis of the Bonin ridge, and that the width of the zone of thin crust is as little as $20 \mathrm{~km}$.

The observed residual gravity anomaly on line OGr1 (370-550 $\mathrm{km}$ in the model) can be explained by a low- 

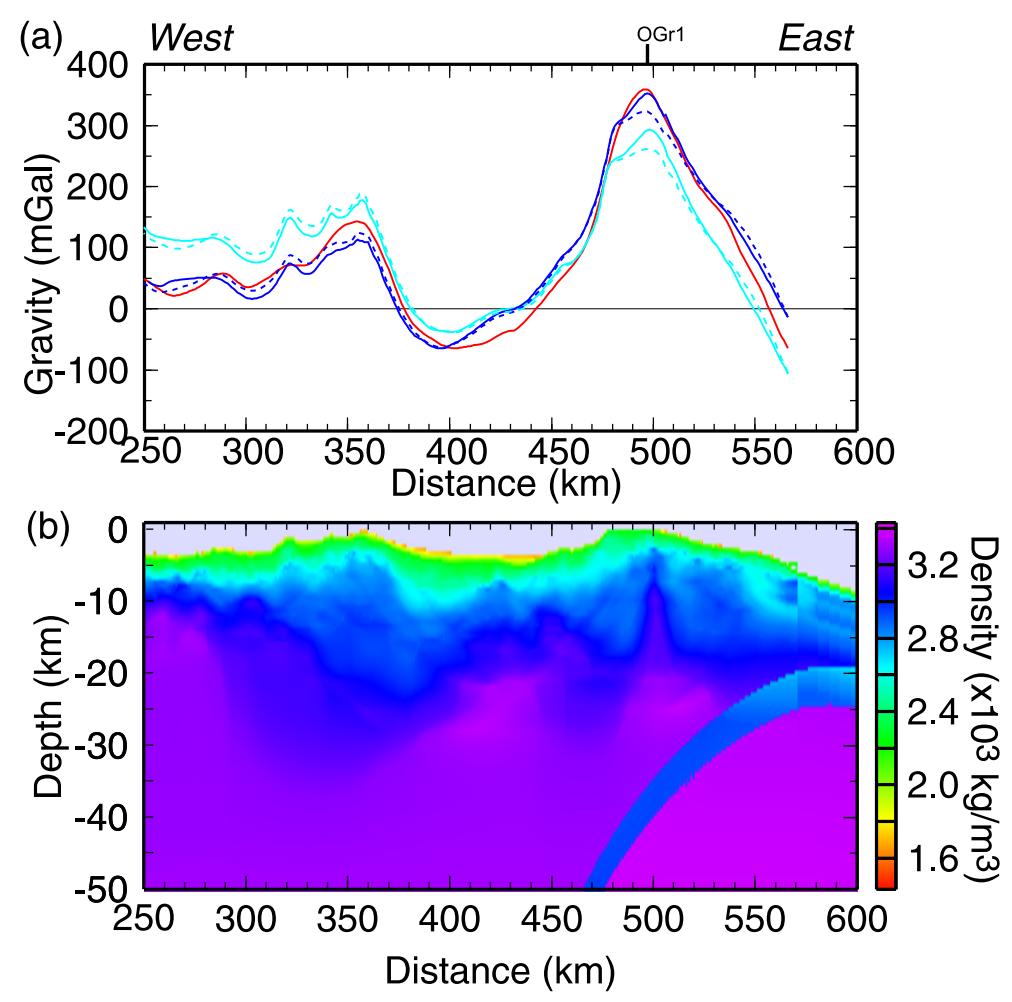

Fig. 9. (a) Calculated and observed gravity anomalies for line SPr2. The red line is the observed free-air gravity anomaly. The dark blue line indicates the calculated gravity anomalies derived from the preferred seismic model (Fig. 7(a)). The broken dark blue line indicates the original model (Takahashi et al., 2009) after addition of the gravity anomaly reflecting the subducting plate. The light blue line indicates the calculated gravity anomaly derived from the preferred seismic model (Fig. 7(a)) and the broken light blue line indicates the original model (Takahashi et al., 2009) without correction for the effect of the subducting plate. (b) Density structure derived from the preferred seismic model (Fig. 7(a)) incorporating the density anomalies of the subducting plate.

density block-like structure in the mantle wedge in the southern part of the profile (Fig. 10). The block structure extends over a depth range of $\sim 30-40 \mathrm{~km}(\sim 10 \mathrm{~km}$ thick) and laterally over $\sim 100 \mathrm{~km}$. The density of the structure is $\sim 350-450 \mathrm{~kg} / \mathrm{m}^{3}$ lower than that of the surrounding mantle and is equivalent to the density of basaltic crust. The lighter material in this structure beneath the southern Bonin ridge may represent part of the Ogasawara plateau that has already been subducted. At the surface, the western edge of the Ogasawara plateau forms a continuous chain of seamounts parallel to the boundary where the Pacific plate subducts under the Bonin arc at the Bonin trench. The crustal thickness of the Ogasawara plateau is estimated to be $\sim 10-20 \mathrm{~km}$ (e.g., Kaneda et al., 2005), which is comparable to the thickness of the block-like structure modeled on line OGr1. To explain the northward increase of the residual anomaly on line OGr1 $(<240 \mathrm{~km}$ in the model $)$, a northward increase of the density of the entire mantle wedge layer is required, such that its density in the north is $\sim 70-80 \mathrm{~kg} / \mathrm{m}^{3}$ higher than that of the southern part of the profile (Fig. 10). In order to interpret this density variation, we speculate that the observed density variation may reflect a temperature difference in the mantle wedge due to the difference in distances from the trench; i.e., the northern part is closer to the trench, where the cold subducting plate is situated more shallowly, than the southern part. A similar high density mantle wedge close to the trench was also demonstrated by a previous gravity study (Furuse and Kono, 2003).

\section{Discussion and Conclusions}

From our analyses of gravity data and seismic profiles along and across the Bonin ridge, we conclude that there is a north-south aligned zone of thin crust ( $\sim 10 \mathrm{~km}$ thick) in the center of the Bonin ridge, and that the width of the zone of thin crust is as little as $\sim 20 \mathrm{~km}$. Although our checkerboard test indicated that our modeling did not wellresolve the eastern end of the SPr2 profile, it did suggest that the crust thickens beneath the trenchward slope of the Bonin ridge.

Forearc seafloor spreading has been proposed as the process most likely to have created the forearc crust along the IBM arc (e.g., Stern and Bloomer, 1992; Shervais, 2001; Stern, 2004; Ishizuka et al., 2006). According to Stern and Bloomer (1992), the forearc spreading stage occurred at 48-45 Ma during which the abrupt sinking of the Pacific plate along a fracture zone caused an adiabatic upwelling of the asthenosphere, which, in turn, produced the forearc oceanic crust. During this stage, melting of the depleted mantle at shallow levels aided by hydrous fluid from the sinking oceanic plate caused boninitic volcanism. This was followed by a transitional stage (45-41 Ma), wherein a transition to true subduction with a down-dip motion of the Pacific plate caused a reorganization of asthenospheric circulation that resulted in a cooling of the forearc and forced the magmatic axis to retreat because of mantle melting at deeper levels. This process caused tholeiitic-calcalkaline andesitic volcanism. During the subsequent stable subduc- 

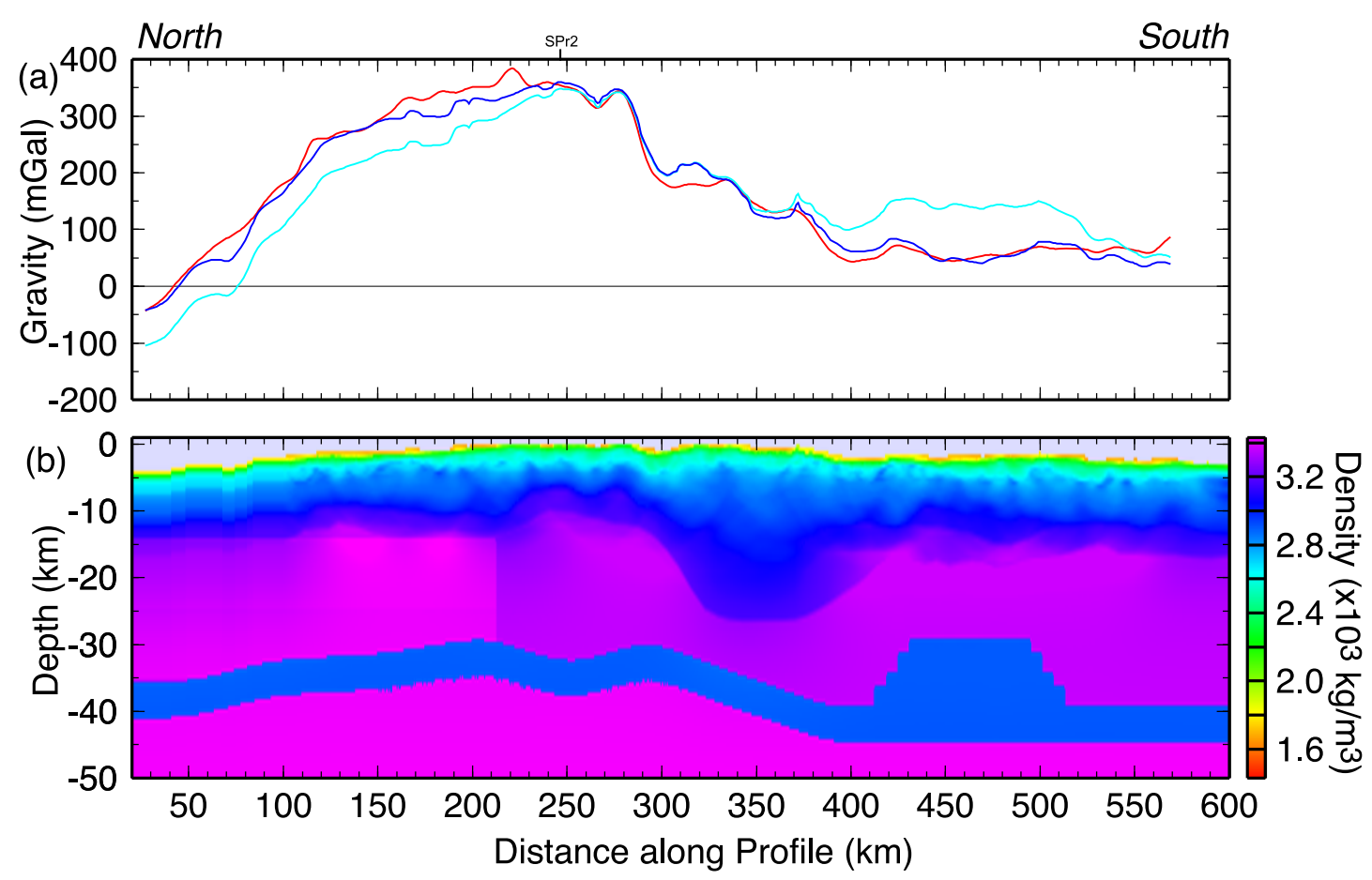

Fig. 10. (a) Calculated and observed gravity anomalies for line OGr1. The red line is the observed free-air gravity anomaly. The light blue line is the calculated gravity anomaly derived from the seismic model of Kodaira et al. (2010) excluding the effects of the subducting plate and density variations in the mantle wedge. The dark blue line is the calculated gravity anomaly derived from the seismic model of Kodaira et al. (2010) incorporating both the effect of the subducting plate and density variations in the mantle wedge.

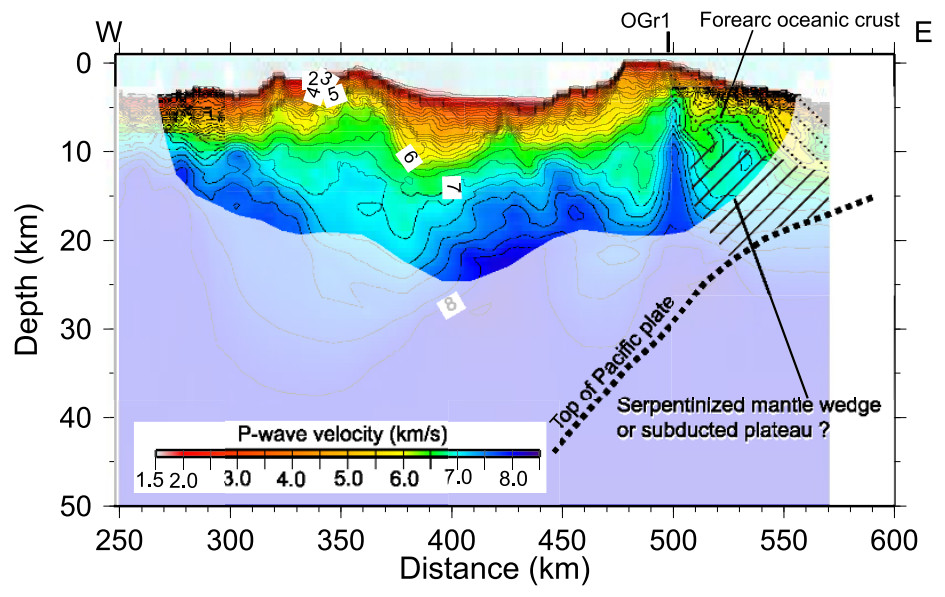

Fig. 11. Line SPr2 showing two interpretations of the modeled thickening of the crust toward the trench. The hatched area indicates the poorly resolved area defined by the checkerboard test (Fig. 7(b)).

tion stage (41 Ma to present), the down-dip motion of the Pacific plate continued.

On the basis of seismic data and the results of a petrological study by Ishizuka et al. (2009), Kodaira et al. (2010) concluded that the block of thin oceanic crust $(\sim 10 \mathrm{~km}$ thick) lies immediately trenchward of the block of thick non-oceanic crust ( $\sim 20 \mathrm{~km}$ thick) that was formed during the transitional stage. It should be noted that the structural variation along OGr1 seems to contradict this conclusion. As described by (Kodaira et al., 2010), a possible explanation for this is that OGr1 is taken obliquely to the boundary between the block of thin oceanic crust and the block of thick non-oceanic crust. The crustal thickening we ob- served from the center of the Bonin ridge to the west is consistent with this conclusion, but it is difficult to explain the thickening of the crust from the center of the Bonin ridge to the trench. Recent diving cruises on the Bonin and Mariana trench slopes (Ishizuka et al., 2009; Reagan et al., 2010; Morishita et al., 2011) discovered oceanic crustal sequences in the form of MORB-like tholeiitic basalts, which were called forearc basalts (FABs). At both the Bonin and Mariana trench slopes, FABs underlie boninites and overlie diabasic and gabbroic rocks. The FABs and gabbroic rocks may be interpreted to represent old trapped oceanic crust from the Philippine Sea plate. However, precise geochemical analysis and age determination of the FABs strongly in- 
dicate that the forearc crustal sequence, including the FABs and gabbroic rocks, was formed by forearc spreading when the Pacific plate began sinking beneath the Philippine Sea plate at around $51 \mathrm{Ma}$ (Reagan et al., 2010). Those geochemical and age data suggest that the thin oceanic crust may extend eastward from the center of the Bonin ridge and beneath the trench slope. Our seismic image, however, appears to contradict this conclusion. Although more seismic data from the trench slope are needed to fully understand the seismic structures where the FABs were discovered, we consider two possible interpretations of the processes that caused the structural variation toward the trench shown by our study: either subduction of the buoyant crust beneath a forearc oceanic crust, or mantle wedge serpentinization (Fig. 11).

To explain the formation of ophiolite, Stern (2004) proposed a model involving subduction of a buoyant oceanic plateau beneath forearc oceanic crust. According to his model (see figure 3 of Stern, 2004), emplacement of an ophiolite above a buoyant crust apparently creates a thick crust on the trenchward side of the forearc. If the buoyant crust underlies forearc oceanic crust only on the trenchward side of the forearc (as shown in figure 3 of Stern, 2004), the crust would thicken trenchward. This model may also explain the strong gravity anomaly in the Bonin ridge area, because subduction of the buoyant crust would force uplift of the forearc. Another possible interpretation is that the model represents serpentinization of a forearc mantle wedge. A recent seismic tomography study by Nakajima et al. (2009) showed a significant decrease of seismic velocity at the tip of the mantle wedge at the northern end of the Izu arc. Although Nakajima et al. (2009) resolved the mantle wedge structure only at the northern edge of the Philippine Sea plate, they also found a region of low $P$-wave velocity and high Poisson's ratio $\left(V_{p} / V_{s}\right)$ at the trenchward tip of the mantle wedge beneath the Kanto region, central Japan. They interpreted this structure to represent serpentinized mantle wedge. If the development of the serpentinized mantle wedge continues to the south along the Izu arc, the crust of the forearc may appear to be thick because the $P$-wave velocity of the serpentinized mantle is comparable to the $P$-wave velocity of the lower crust (e.g., Hyndman and Peacock, 2003). The Poisson's ratio structure at the forearc of the Bonin arc is fundamental to identifying the most appropriate model. To obtain the $V_{p} / V_{s}$ structure, future studies should include arc-parallel active-source profiles as well as passive seismic studies.

In conclusion, our re-modeling of both gravity data and cross-ridge and ridge-parallel seismic data along the Bonin ridge showed the existence of a 20-km-wide, north-south aligned zone of thin crust $(\sim 10 \mathrm{~km}$ thick) along the axis of the Bonin ridge. This structure is consistent with a model whereby forearc oceanic crust was created by forearc spreading during the initial stage of arc crust formation. Although a more detailed investigation is needed, the trenchward thickening of forearc crust revealed by our modeling is interpreted as either a result of the subduction of the buoyant crust beneath forearc oceanic crust, or the existence of a serpentinized mantle wedge for which the seismic velocity gives the impression of thick crust.
Acknowledgments. This study was funded by the Institute for Research on Earth Evolution, Japan Agency for Marine-Earth Science and Technology, and partially supported by Grant-in-Aid for Creative Scientific Research (19GS0211) and Grant-in-Aid for Scientific Research (B) (20340122). We gratefully acknowledge the help of the captain, crew, and technical staff on board R/V Kaiyo during the acquisition of the seismic data.

\section{References}

Bibee, L. D., G. G. Shor, Jr., and R. S. Lu, Inter-arc spreading in the Mariana Trough, Marine Geol., 35, 183-197, 1980.

Blakely, R. J., Potential Theory in Gravity \& Magnetic Applications, 441 pp., Cambridge University Press, New York, 1996.

Calvert, A. J., S. L. Klemperer, N. Takahashi, and B. C. Kerr, Threedimensional crustal structure of the Mariana island arc from seismic tomography, J. Geophys. Res., 113, B01406, doi:10.1029/2007JB004939, 2008.

Furuse, N. and Y. Kono, Slab residual gravity anomaly: gravity reduction due to subducting plates beneath the Japanese Islands, J. Geodyn., 36, 497-514, 2003

Honza, E. and K. Tamaki, The Bonin Arc, in The Ocean Basins and Margins, edited by A. E. Nairn, F. G. Stehli, and S. Uyeda, pp. 459502, Plenum Publishing Co., 1985.

Hyndman, R. D. and S. M. Peacock, Serpentinization of the forearc mantle, Earth Planet. Sci. Lett., 212, 417-432, 2003.

International Seismological Centre, Bulletin Disks 1-9 (CD-ROM), Internatl. Seis. Cent., Thatcham, United Kingdom, 2001.

Ishihara, T., F. Murakami, T. Miyazaki, and K. Nishimura, Gravity survey, In Geological investigation of the Ogasawara (Bonin) and northern Mariana arcs, Geol. Surv. Japan Cruise Report No. 14, edited by Honza, Inoue, and Ishihara, 45-78, 1981.

Ishizuka, O., K. Uto, M. Yuasa, and A. G. Hochstaedter, Volcanism in the earliest stage of back-arc rifting in the Izu-Bonin arc revealed by laserheating ${ }^{40} \mathrm{Ar} /{ }^{39} \mathrm{Ar}$ dating, J. Volcanol. Geotherm. Res., 120, 1-85, 2002.

Ishizuka, O., J. Kimura, Y. B. Li, R. J. Stern, M. K. Reagan, R. N. Taylor, Y. Ohara, S. H. Bloomer, T. Ishii, U. S. Hargrove, III, and S. Haraguchi, Early stages in the evolution of Izu-Bonin arc volcanism: New age, chemical, and isotopic constraints, Earth Planet. Sci. Lett., 250, 385401, 2006.

Ishizuka, O., M. Yuasa, K. Tani, S. Umino, M. K. Reagan, K. Kanayama, Y. Harigane, and Y. Miyajima, In-situ arc crustal section found at the initial stage of oceanic island arc-Diving survey in the Izu-Bonin forearc, EOS Trans, AGU, 90(52), Fall Meet. Suppl., Abstract T32A-05, 2009.

Kanazawa, T. and H. Shiobara, Newly developed ocean bottom seismometer, Prog. Abst. Japan Earth and Planetary Science Joint Meeting, 2, 240, 1994.

Kaneda, K., A. Nishizawa, and J. Kasahara, Crustal structure model of the Ogasawara Plateau colliding with the Philippine Sea Plate, Japan Earth Planet. Sci. Joint Meet., abstract J078-011, 2005.

Kodaira, S., T. Sato, N. Takahashi, A. Ito, Y. Tamura, Y. Tatsumi, and Y. Kanda, Seismological evidence for variable growth of crust along the Izu intra-oceanic arc, J. Geophys. Res., 112, B05104, doi:10.1029/2006JB004593, 2007a.

Kodaira, S., T. Sato, N. Takahashi, S. Miura, Y. Tamura, Y. Tatsumi, and Y. Kaneda, New seismological constraints on growth of continental crust in the Izu-Bonin intra-oceanic arc, Geology, 35, 1031-1034, doi:10.1130G23901A, 2007b.

Kodaira, S., T. Sato, N. Takahashi, M. Yamashita, T. No, and Y. Kaneda, Seismic imaging of a possible paleo-arc in the Izu-Bonin intra-oceanic arc and its implications for arc evolution processes, Geochem. Geophys. Geosyst., 9, doi:10.1029/2008GC002073, 2008.

Kodaira, S., N. Noguchi, N. Takahashi, O. Ishizuka, and Y. Kaneda, Evolution from fore-arc oceanic crust to island arc crust: A seismic study along the Izu-Bonin forearc, J. Geophys. Res., 115, B09102, doi:10.1029/2009JB006968, 2010.

Ludwig, W. J., J. E. Nafe, and C. L. Drake, Seismic refraction, in The Sea, edited by A. E. Maxwell, vol. 4, pp. 53-84, Interscience, New York, 1970

Morishita, T., K. Tani, H. Shukuno, Y. Harigane, A. Tamura, H. Kumagai, and E. Hellebrand, Diversity of melt conduits in the Izu -Bonin-Mariana forearc mantle: implications for the earliest stage of arc magmatism, Geology, 39(4), 411-414, 2011.

Nakajima, J., Y. Tsuji, and A. Hasegawa, Seismic evidence for thermallycontrolled dehydration reaction in subducting oceanic crust, Geophys. 
Res. Lett., 36, L03303, doi:10.1029/2008GL036865, 2009.

Pearce, J. A., S. R. Van der Laan, R. J. Arculus, B. J. Murton, T. Ishii, W. W. Peate, and I. J. Parkinson, Boninite and harzburgite from ODP Leg 125 (Bonin-Mariana forearc): A case study of magma genesis during the initial stages of subduction, in Proceedings of the Ocean Drilling Program Scientific Results, edited by P. Fryer, J. A. Pearce, and L. B. Stokking, et al., 125, 623-659, College Station Texas, Ocean Drilling Program, 1992.

Reagan, M. K., O. Ishizuka, R. J. Stern, K. A. Kelly, Y. Ohara, J. Blichert-Toft, S. H. Bloomer, J. Cash, P. Fryer, B. B. Hanan, R. Hickey-Vargas, T. Ishii, J. Kimura, D. W. Peate, M. C. Rowe, and M. Woods, Fore-arc basalts and subduction initiation in the IzuBonin-Mariana system, Geochem. Geophys. Geosyst., 11, Q03X12, doi:10.1029/2009GC002871, 2010.

Sandwell, D. T. and W. H. F. Smith, Marine gravity anomaly from Geosat and ERS 1 satellite altimetry, J. Geophys. Res., 102, 10,039-10,054, 1997.

Sato, T., S. Kodaira, N. Takahashi, Y. Tatsumi, and Y. Kaneda, Amplitude modeling of the seismic reflectors in the crust-mantle transition layer beneath the volcanic front along the northern Izu-Bonin island arc, Geochem. Geophys. Geosyst., 10, doi:10.1029/2008GC001990, 2009.

Shervais, J. W., Birth, death, and resurrection: The life cycle of suprasubduction zone ophiolites, Geochem. Geophys. Geosyst., 2, Paper number 2000GC000080, 2001.

Shinohara, M., K. Suyehiro, S. Matsuda, and K. Ozawa, Digital recording ocean bottom seismometer using portable digital audio tape recorder, $J$. Jpn. Soc. Mar. Surv. Tech., 5, 21-31, 1993.

Stern, R. J., Subduction initiation: spontaneous and induced, Earth Planet. Sci. Lett., 226, 275-292, doi:10.1016/j.epsl.2004.08.007, 2004.

Stern, R. J. and S. H. Bloomer, Subduction zone infancy: Examples from the Eocene Izu-Bonin-Mariana and Jurassic California, Geol. Soc. Am. Bull., 104, 1621-1636, 1992.

Suyehiro, K., N. Takahashi, Y. Ariie, Y. Yokoi, R. Hino, M. Shinohara, T. Kanazawa, N. Hirata, H. Tokuyama, and A. Taira, Continental crust, crustal underplating and low-Q upper mantle beneath an oceanic island arc, Science, 272, 390-392, 1996.
Takahashi, N., S. Kodaira, S. L. Klemperer, Y. Tatsumi, Y. Kaneda, and K. Suyehiro, Crustal structure and evolution of Mariana intra-oceanic island arc, Geology, 35, 203-206, doi:10.1130/G23212A.1, 2007.

Takahashi, N., S. Kodaira, Y. Tatsumi, Y. Kaneda, and K. Suyehiro, Structure and growth of the Izu-Bonin-Mariana arc crust: 1. Seismic constraint on crust and mantle structure of the Mariana arc-back-arc system, J. Geophys. Res., 113, B01104, doi:10.1029/2007JB005120, 2008a.

Takahashi, N., T. Takahashi, S. Kodaira, and Y. Kaneda, Refraction and reflection Seismic profilings to investigate the Eocene arc-KY0715 cruise-, JAMSTEC-R, 2008b.

Takahashi, N., S. Kodaira, T. Tatsumi, M. Yamashita, T. Sato, Y. Kaiho, S. Miura, T. No, K. Takizawa, and Y. Kaneda, Structural variations of arc crusts and rifted margins in southern Izu-Ogasawara arc-back arc system, Geochem. Geophys. Geosyst., doi:10.1029/2008GC002146, 2009.

Tatsumi, Y., H. Shukuno, K. Tani, N. Takahashi, S. Kodaira, and T. Kogiso, Structure and growth of the Izu-Bonin-Mariana arc crust: 2. Role of crust-mantle transformation and the transparent Moho in arc crust evolution, J. Geophys. Res., 113, B02203, doi:10.1029/2007JB005121, 2008.

Taylor, R. N. and R. W. Nesbitt, Arc volcanism in an extensional regime at the initiation of subduction: a geochemical study of Hahajima, Bonin Islands, Japan, in Volcanism Associated with Extension at Consuming Plate Margins, edited by J. Smellie, Geological Society Special Publications, 81, Geological Society of London, London, 1995.

Yamazaki, T. and M. Yuasa, Possible Miocene rifting of the Izu-Ogasawara (Bonin) arc deduced from magnetic anomalies, Island Arc, 7, 374-382, 1998.

Zhang, U. and M. N. Toksöz, Nonlinear refraction travel time tomography, Geophysics, 63, 1726-1737, 1998.

S. Kodaira (e-mail: kodaira@jamstec.go.jp), T. Fujiwara, N. Noguchi, and N. Takahashi 